\title{
International Journal of Zoological
Investigations \\ Physiological Role of a Calcitonin-Like Substance in the Life Cycle of the Lamprey, Lampetra japonica (Cyclostomata)
}

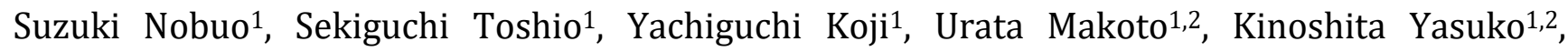 \\ Matsubara Hajime ${ }^{3}$, Asahina Kiyoshi ${ }^{4}$, Kambegawa Akira ${ }^{5}$ and Srivastav Ajai Kumar6* \\ ${ }^{1}$ Noto Marine Laboratory, Institute of Nature and Environmental Technology, Kanazawa University, Ogi, Noto-cho, Ishikawa \\ 927-0553, Japan \\ 2Institute of Noto SATOUMI Education Research, Ogi, Noto-cho, Ishikawa 927-0553, Japan \\ ${ }^{3}$ Noto Center for Fisheries Science and Technology, Kanazawa University, Ossaka, Noto-cho, Ishikawa 927-0552, Japan \\ ${ }^{4}$ Department of Marine Science and Resources, College of Bioresource Sciences, Nihon University, Fujisawa, Kanagawa 252-0880, \\ Japan \\ 5The Kambegawa Laboratory, Komae, Tokyo 201-0013, Japan \\ 6Department of Zoology, D.D.U. Gorakhpur University, Gorakhpur 273 009, India
}

*Corresponding Author

Received: $13^{\text {th }}$ September, 2019

Accepted: 14th October, 2019

https://doi.org/10.33745/ijzi.2019.v05i02.003

\begin{abstract}
The present study elucidates the physiological role of a calcitonin (CT)-like substance in the lamprey (Lampetra japonica) captured in a river. A CT-like substance in the plasma of lampreys ( $\mathrm{n}=13$, both sexes) was examined by an enzyme-linked immunosorbent assay using an anti-salmon CT serum when they were transferred from freshwater $(\mathrm{FW})$ to $1 / 3$ seawater $(1 / 3 \mathrm{SW})$. After keeping them in 1/3 SW for one day, the CT-like substance in $1 / 3 \mathrm{SW}$-adapted lampreys was significantly higher than that in FW-adapted lampreys. This substance was significantly correlated with the gonad somatic index (GSI) in males; however, the GSI could not be measured in post-spawned females. The present study is in agreement with a previous study showing that the CT-like substance had a significant correlation with the GSI in both sexes. This species of lamprey is born in a river and then migrates from FW to SW after metamorphosis. Subsequently, the lamprey grows up in the sea. Thereafter, it migrates from SW to FW and then spawns in the river to complete its life cycle. The results obtained here suggest that the CT-like substance plays important roles in their migration from FW to SW and their sexual maturation after migrating from SW to FW during their life cycle.
\end{abstract}

Keywords: Calcitonin-like substance, Gonad somatic index, Seawater adaptation, Sexual maturation, Migration, Lamprey

Citation: Suzuki Nobuo, Sekiguchi Toshio, Yachiguchi Koji, Urata Makoto, Kinoshita Yasuko, Matsubara Hajime, Asahina Kiyoshi, Kambegawa Akira and Srivastav Ajai Kumar: Physiological role of a calcitonin-like substance in the life cycle of the lamprey, Lampetra japonica (Cyclostomata). Intern. J. Zool. Invest. 5 (2): 23-30, 2019 https://doi.org/10.33745/ijzi.2019.v05i02.003 


\section{Introduction}

Calcitonin (CT) consists of 32 amino acids and is a hypocalcemic hormone that can mineralize bones by suppressing the activities of osteoclasts in mammals (Kameda, 2017; Hay et al., 2018). This hormone is secreted by the C-cells of the thyroid gland in mammals and by the ultimobranchial gland (UBG) in non-mammalian vertebrates (Kameda, 2017).

From morphological observations (Watzka, 1933) and a rat bioassay for hypocalcemic activity (Copp et al., 1970) in the branchial region, which possibly contains UBG, it has been concluded that Cyclostomata, such as lampreys and hagfishes, have no CTproducing cells. However, using Western blotting methods, a CT-like substance has been detected in the plasma of the lamprey (Lampetra japonica), and the molecular weight of this substance was estimated to be $3.5 \mathrm{kDa}$, which is equal to that of salmon CT (Suzuki, 2001). In other species of Cyclostomata (hagfish, Eptatretus burgeri), the immunoreactive substance $(3.5 \mathrm{kDa})$ was also present and was shown to have hypocalcemic and hypophosphatemic activities in rats (Suzuki, 1995). Therefore, this CT-like substance is secreted from a yet unidentified organ or cells and may have some physiological role in Cyclostomata.

All hagfishes live in the sea; some lampreys move to the sea after metamorphosis in freshwater (FW) and take several years to become sexually mature. Thereafter, lampreys undergo a spawning migration from seawater (SW) to FW during their life cycle (Morris, 1958). Therefore, lampreys must regulate their body fluid according to changes in the environmental water. It has been reported that the lamprey
(Lampetra fluviatilis) adapted to hyperosmotic media using kidney function: reduced glomerular filtration rate, changed urine composition, and increased water resorption (Logan et al., 1980a; McVicar and Rankin, 1985; Rankin, 2002). Furthermore, lampreys (Petromyzon marinus) as well as teleosts have mitochondria-rich cells in their gills. These cells are involved in osmoregulation (Peek and Youson, 1979; Bartels et al., 1996, 1998). However, there is little information about hormonal regulation in the osmoregulation of lampreys (Bentley, 1998). A CT-like substance in lampreys may function in correlation with changes in the environmental water over its life cycle.

To examine the physiological role of the CT-like substance, we measured the plasma level of this substance by an enzyme-linked immunosorbent assay (ELISA) using an antisalmon CT serum in the lamprey, Lampetra japonica, when they were transferred from FW to diluted SW. In a previous report (Suzuki, 2001), the correlation between the CT-like substance and gonadal maturation in the lamprey was recognized. In the present study, we confirmed this correlation.

Considering the present results along with those of previous studies, we discussed the physiological significance of a CT-like substance in the lamprey, Lampetra japonica.

\section{Materials and Methods}

\section{Animal:}

The mature lampreys, Lampetra japonica $(\mathrm{n}=$ 13: 10 males and 3 females) migrated from the sea to the river, were caught in the lower reaches of the Machino River (Ishikawa Prefecture) (Fig. 1). Collected lampreys were 
carried to the laboratory. Prior to the experiments, fish were acclimatized in the aquarium $(120 \mathrm{~cm} \times 60 \mathrm{~cm} \times 45 \mathrm{~cm})$ for 3 days after collection. These lampreys were anesthetized with $0.03 \%$ ethyl 3aminobenzoate methanesulfonic acid salt (MS-222, Aldrich Chemical Company, Inc., USA), and then their body weight was measured. Thereafter, we labeled the head, fins, and tail with thread to identify each lamprey. Thereafter, blood samples (1-2 ml) were collected from the caudal vessel with heparinized syringes, hematocrit values were measured, and samples were centrifuged at $25,000 \times \mathrm{g}$ for $10 \mathrm{~min}$ at $4 \mathrm{C}$. The plasma was immediately frozen and kept at $-80 \mathrm{C}$ until use. Lampreys were then transferred into the diluted SW (1/3 SW) and kept for one day. The salinity of the diluted SW was 11.13 practical salinity units. After blood sampling, each gonad was dissected under anesthesia, and the gonad somatic index (GSI) was calculated by weight of gonad (g)/weight of body (g) x 100 (\%).

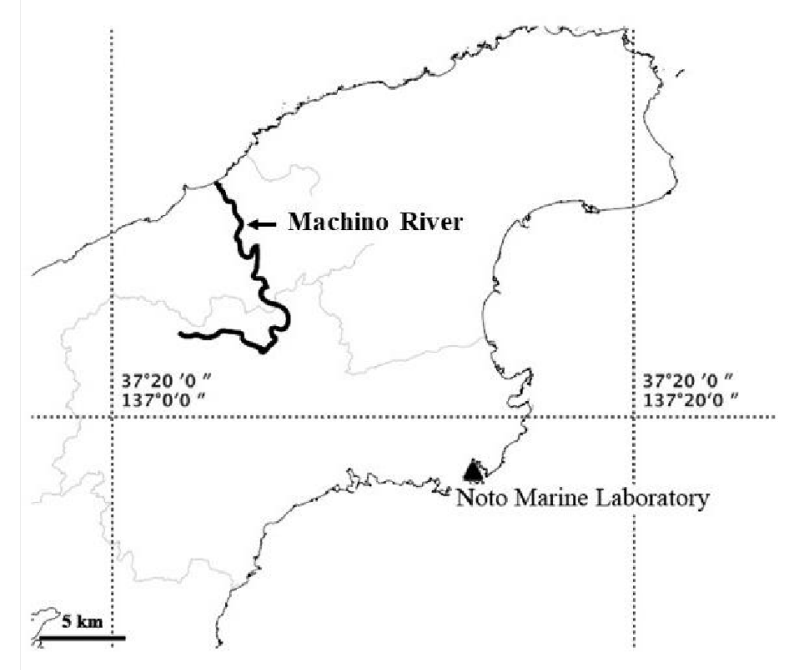

Fig. 1: Map of the area from which lampreys were collected for the present study. This map is based on Digital Map 25000 (Map Image) provided by the Geospatial Information Authority of Japan. Arrow: Machino River; $\boldsymbol{\Delta}$ : Noto Marine Laboratory of Kanazawa University.
Measurement of plasma CT-like substance by ELISA

ELISA procedures have been described in detail by Suzuki (2001). The detection limit was $25 \mathrm{pg} / \mathrm{ml}$. The specificity of the antisalmon CT serum (No. 626, Cosmo Bio Co., Ltd., Japan) was checked using peptide hormones (1-34 bovine parathyroid hormone and human calcitonin gene-related peptide). This antiserum did not cross-react with these peptide hormones. Data of males and females are pooled in the present study.

\section{Statistical analysis}

All results are expressed as the mean $\pm \mathrm{SE}$ $(\mathrm{n}=13)$. By transferring from $\mathrm{FW}$ to $1 / 3 \mathrm{SW}$, the statistically significant difference between the values of the control and the experimental group was assessed by Student's t-test. The relationship of the plasma CT-like substance with the GSI was examined using a linear regression analysis. The significance level chosen was $\mathrm{P}<0.05$.

\section{Results and Discussion}

Changes in body weight and hematocrit value after transfer from $F W$ to $1 / 3 \mathrm{SW}$

Following a transfer from FW into $1 / 3 \mathrm{SW}$, the body weight (Table 1) decreased from $143.7 \pm$ 11.4 to $124.9 \pm 9.0(\mathrm{~g})$, while the hematocrit value (Table 1) increased significantly $(P<$ $0.05)$ from $34.5 \pm 2.0$ to $42.9 \pm 2.8(\%)$. As a result of the transfer from $\mathrm{FW}$ to $1 / 3 \mathrm{SW}$, changes in the body weight and hematocrit value were $13 \%$ and $24 \%$, respectively. These results indicate that the lamprey was affected by dehydration when transferred from FW to 1/3 SW. 
Table 1: Changes in body weight (g) and hematocrit value (\%) when lampreys, Lampetra japonica, were transferred from freshwater (FW) to diluted sea water $(1 / 3 \mathrm{SW})$

\begin{tabular}{|c|c|c|c|c|c|c|}
\hline & \multicolumn{2}{|c|}{ FW } & \multicolumn{2}{|c|}{$1 / 3 \mathrm{SW}$} & \multicolumn{2}{|c|}{ The ratio of $(1 / 3 \mathrm{SW}) / \mathrm{FW}$} \\
\hline & Body weight & Hematocrit value & Body weight & Hematocrit value & Body weight & Hematocrit value \\
\hline No. 1 & 109.4 & 43 & 96.8 & 51 & 0.88 & 1.18 \\
\hline No. 2 & 161.8 & 31 & 152.6 & 33 & 0.94 & 1.06 \\
\hline No. 3 & 142.8 & 36 & 123.0 & 51 & 0.86 & 1.42 \\
\hline No. 4 & 132.0 & 36 & 115.0 & 51 & 0.87 & 1.42 \\
\hline No. 5 & 237.0 & 19 & 183.0 & 23 & 0.77 & 1.21 \\
\hline No. 6 & 186.0 & 36 & 160.0 & 50 & 0.86 & 1.38 \\
\hline No. 7 & 102.0 & 31 & 80.2 & 44 & 0.79 & 1.42 \\
\hline No. 8 & 193.0 & 44 & 170.3 & 55 & 0.88 & 1.25 \\
\hline No. 9 & 124.0 & 33 & 103.0 & 39 & 0.83 & 1.18 \\
\hline No. 10 & 90.4 & 24 & 85.1 & 28 & 0.94 & 1.17 \\
\hline No. 11 & 120.0 & 44 & 110.0 & 50 & 0.92 & 1.14 \\
\hline No. 12 & 128.7 & 34 & 118.3 & 41 & 0.92 & 1.21 \\
\hline No. 13 & 141.5 & 37 & 126.5 & 42 & 0.89 & 1.14 \\
\hline Mean \pm SE & $143.7 \pm 11.4$ & $34.5 \pm 2.0$ & $124.9 \pm 9.0$ & $42.9 \pm 2.8$ & $0.87 \pm 0.01$ & $1.24 \pm 0.03$ \\
\hline
\end{tabular}


Table 2: Changes in plasma CT-like substance $(\mathrm{pg} / \mathrm{ml})$ when lampreys, Lampetra japonica, were transferred from freshwater (FW) to diluted sea water $(1 / 3 \mathrm{SW})$.

\begin{tabular}{rrrc}
\hline & FW & $1 / 3 \mathrm{SW}$ & The ratio of $(1 / 3 \mathrm{SW}) / \mathrm{FW}$ \\
\hline No. 1 & 1199.4 & 4335.6 & 3.61 \\
No. 2 & 112.8 & 1411.8 & 12.52 \\
No. 3 & 948.6 & 5314.8 & 5.60 \\
No. 4 & 282.6 & 1615.8 & 5.72 \\
No. 5 & 271.8 & 2563.2 & 9.43 \\
No. 6 & 776.4 & 2327.7 & 3.00 \\
No. 7 & 628.2 & 1803.3 & 2.87 \\
No. 8 & 41.4 & 247.2 & 5.97 \\
No. 9 & 1397.1 & 5946.0 & 4.26 \\
No. 10 & 192.3 & 1987.5 & 10.34 \\
No. 11 & 1383.4 & 3103.2 & 2.24 \\
No. 12 & 1410.6 & 3252.3 & 2.31 \\
No. 13 & 1540.2 & 2831.7 & 1.84 \\
\hline Mean \pm SE & $783.5 \pm 155.9$ & $2826.2 \pm 443.2$ & $5.36 \pm 0.95$ \\
\hline
\end{tabular}

Changes in the plasma CT-like substance after transfer from $F W$ to $1 / 3 \mathrm{SW}$

The level of a CT-like substance in lamprey plasma was increased after the transfer from FW to $1 / 3$ SW (Fig. 2). A significant difference $(P<0.001)$ was obtained between FW- and $1 / 3$ SW-adapted lampreys. This substance showed a 5.36-time increase (Table 2).

By transferring lampreys from $\mathrm{FW}$ to $1 / 3$ SW, the CT-like substance in the plasma increased considerably (Fig. 2). The increase of this substance (5.36 times) was higher than that of the hematocrit value (1.24 times) with the dewatering of each lamprey (Tables 1,2). These results indicate that a CT-like substance had been secreted from an unidentified organ or cells.

Arginine-vasotocin, which is a neurohypophysial hormone, is present in representatives of all main groups of fish, including cyclostomes (Bentley, 1998; Lane et al., 1998; Suzuki et al., 1995), and is a diuretic in FW teleosts (Maetz et al., 1964; Jones et al., 1969; Sawyer et al., 1982). In the lamprey (Lampetra fluviatilis), plasma electrolyte concentrations were maintained well below corresponding concentrations in the external environment by kidney functions, such as the glomerular filtration rate and water resorption rate (Logan et al., 1980 a, b). However, there were no differences in the plasma levels of arginine-vasotocin in the lamprey (Lampetra japonica) during the transfer from $\mathrm{FW}$ to $1 / 2 \mathrm{SW}$, although the contents of the pituitary gland declined in $1 / 2$ SW (Uchiyama et al., 1994). In the lamprey (Lampetra japonica), therefore, some points remain unclear regarding the function of arginine-vasotocin in osmoregulation. On the other hand, the present study indicates that the CT-like substance increased considerably after transfer to $1 / 3 \mathrm{SW}$ (Fig. 2). This result 
suggests that this substance is involved in SW adaptation in the lamprey (Lampetra japonica). Analyses of excretory organs such as the kidney and gill on which this substance possibly acted will provide some information for the study of lamprey osmoregulation.

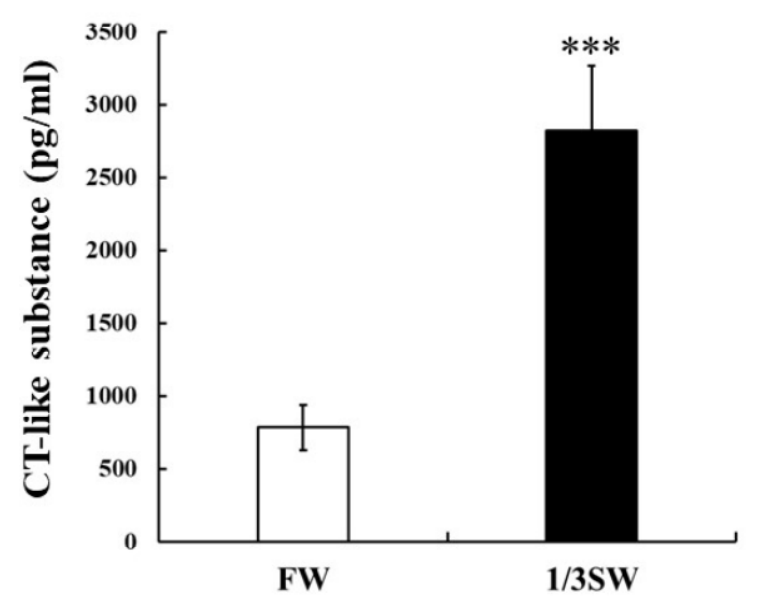

Fig. 2: Changes in a plasma calcitonin (CT)-like substance of lampreys transferred from FW to $1 / 3 \mathrm{SW}$. *** indicates a statistically significant difference at $p<$ 0.001 between FW- and 1/3 SW-adapted lampreys.

Relationship between the CT-like substance and the GSI

There exists a significant correlation $(r=$ 0.848; $p<0.01 ; \mathrm{n}=10$ ) between the CT-like substance and the GSI in males (Fig. 3); however, the GSI could not be measured in post-spawned females.

In the male sockeye salmon (Oncorhynchus nerka), the plasma CT level increased during spawning (Watts et al., 1975). In addition, it was reported that CT regulates the secretion of testosterone in rats (Wang et al., 1994). On the other hand, in female eels (Anguilla japonica), rainbow trout (Salmo gairdneri), and brown trout (Salmo trutta), the increase of plasma CT occurred before ovulation (Yamauchi et al., 1978; Björnsson et al., 1986; Norberg et al., 1989). Furthermore, Greenberg et al. (1986) demonstrated that, in rats, estrogen stimulates CT secretion in thyroid C-cells in vitro. The injection of estrogen induced CT secretion in rainbow trout (Salmo gairdneri) (Björnsson et al., 1989), goldfish (Carassius auratus auratus)(Suzuki et al., 2004), and stingrays (Dasyatis akajei) (Takagi et al., 2019). Moreover, a previous study (Suzuki, 2001) indicated that there was a significant relationship between the CT-like substance and the GSI in females as well as males. Considering these results along with those of the present study, we believe that this substance has important functions in the maturation of both sexes in the lamprey (Lampetra japonica) as well as in other vertebrates. To elucidate the function of this substance in the gonad, we plan to study the cloning of the CT receptor in the lamprey (Lampetra japonica).

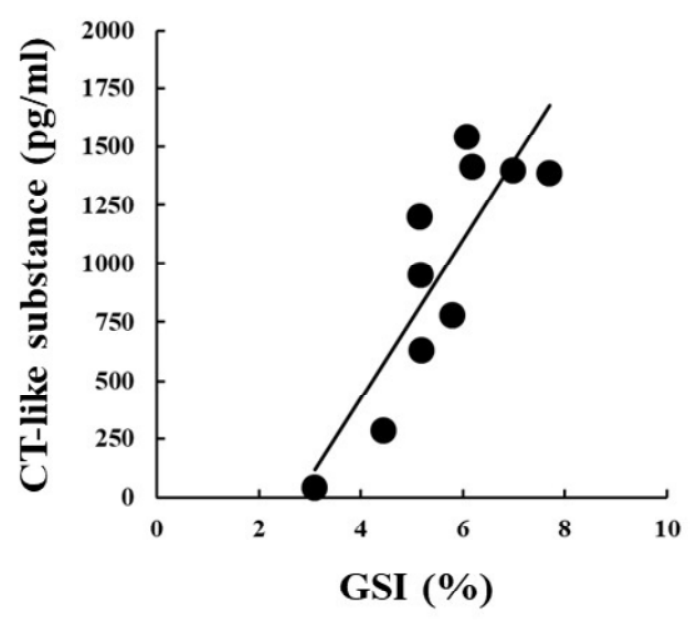

Fig. 3: Plasma CT-like substance and gonad somatic index (GSI) in male lampreys. The black circles indicate each value of male lampreys. A significant correlation $(r$ $=0.848, p<0.01$ ) was found between the plasma CTlike substance and the GSI.

In the present study, a CT-like substance was detected in the plasma of the lamprey (Lampetra japonica). A previous study demonstrated that the molecular weight of this substance was equal to that of salmon CT 
(Suzuki, 2001). In the plasma of the hagfish (Eptatretus burgeri), a substance of the same molecular weight has also been detected that has been found to possess bioactivity in rats (Suzuki, 1995). Therefore, these substances in the plasma of the lamprey (Lampetra japonica) and the hagfish (Eptatretus burgeri) may be CT. To determine the nucleotide sequence of these substances, genomic and reverse-transcription PCR and rapid amplification of cDNA ends were performed using several sets of primers. However, no positive results have, thus far, been obtained. Attempts are underway to purify the CT-like substance from plasma and to determine its sequence.

\section{Conclusion}

Lampreys (Lampetra japonica) hatch in FW and then move to the sea. In this migration, a CT-like substance might play a role in SW

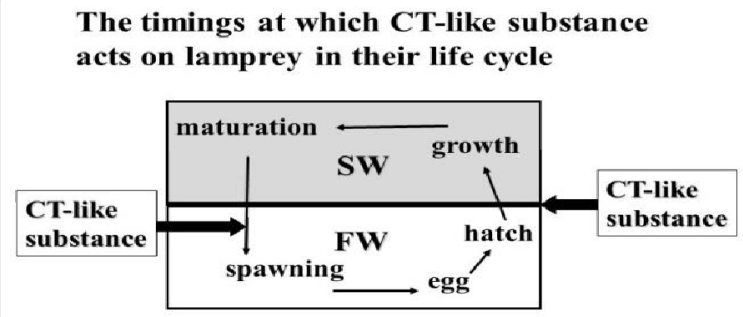

Fig. 4: Physiological significance of a CT-like substance in the life cycle of the lamprey. The timings at which CT-like substance acts on lampreys in their life cycle are indicated. Lampreys (Lampetra japonica) migrate from FW to SW after hatching and metamorphose and grow up in the sea for several years. Thereafter, they undergo a spawning migration from SW to FW to complete the life cycle. A CT-like substance may play an important role in the migration from FW to SW and sexual maturation after migration from SW to FW.

adaptation. After a subsequent spawning migration from SW to $\mathrm{FW}$, this substance appears to play some role in sexual maturation. A previous study (Suzuki, 2001) indicated that this substance was not detected in the plasma of SW-adapted lampreys (Lampetra japonica) just before the spawning migration. In the lamprey life cycle, therefore, it is possible that this substance is synthesized at a special time and plays some roles under special conditions, such as migration and sexual maturation (Fig. 4).

\section{Acknowledgement}

The authors are grateful to Mr. Y. Ukon for collecting the lampreys. This study was supported in part by grants to N. S. (Kanazawa University CHOZEN project) and to T. S. (Grant-in-Aid for Scientific Research [C] No. 18K06312 by JSPS). This work was partly supported by the cooperative research program of the Institute of Nature and Environmental Technology, Kanazawa University to A. K. S. ( Accept Number 18035).

\section{References}

Bartels H, Moldenhauer A and Potter IC. (1996) Changes in the apical surface of chloride cells following acclimation of lampreys to seawater. Am. J. Physiol. 270: R125-133.

Bartels H, Potter IC, Pirlich K and Mallatt J. (1998) Categorization of the mitochondria-rich cells in the gill epithelium of the freshwater phases in the life cycle of lamprey. Cell Tissue Res. 291: 337-349.

Bentley PJ. (1998) Comparative Vertebrate Endocrinology. $3^{\text {rd }}$ ed, Cambridge University Press, Cambrige.

Björnsson B Th, Haux C, Förlin L and Deftos LJ. (1986) The involvement of calcitonin in the reproductive physiology of the rainbow trout. J. Endocrinol. 108: 17-23.

Björnsson B Th, Haux C, Bern HA and Deftos LJ. (1989) 17ßestradiol increases plasma calcitonin levels in salmonid fish. Endocrinology 125:1754-1759.

Copp DH, Brooks CE, Low BS, Newsome F, O'dor RK, Parkes CO, Walker V and Watts EG. (1970) Calcitonin and ultimobranchial function in lower vertebrates. In: Taylar S (ed), Calcitonin, Heinemann, London, pp 281-294.

Greenberg C, Kukreja SC, Bowser EN, Hargis GK, Henderson WJ and Williams GA. (1986) Effects of estradiol and progesterone on calcitonin secretion. Endocrinology 118: 2594-2598.

Hay DL, Garelja ML, Poyner DR and Walker CS. (2018) Update on the pharmacology of calcitonin/CGRP 
family of peptides: IUPHAR Review $25 . \mathrm{Br}$. J.Pharmacol. 175: 3-17.

Jones CI, Chan DKO and Rankin JC. (1969) Renal function in the European eel (Anguilla anguilla): II Effects of the caudal neurosecretory system, corpuscles of Stannius, neurohypophysial peptides and vasoactive substances. J. Endocrinol. 43: 21-31.

Kameda Y. (2017) Morphological and molecular evolution of the ultimobranchial gland of nonmammalian vertebrates, with special reference to the chicken C cells. Dev. Dyn. 246: 719-739.

Lane TF, Sower SA and Kawauchi H. (1988) Arginine vasotocin from the pituitary gland of the lamprey (Petromyzon marinus): Isolation and amino acid sequence. Gen. Comp. Endocrinol. 70: 152-157.

Logan AG, Morris R and Rankin JC. (1980a) A micropuncture study of kidney function in the river lamprey Lampetra fluviatilis adapted to sea water. J. Exp. Biol. 88: 239-247.

Logan AG, Moriarty RJ and Rankin JC. (1980b) A micropuncture study of kidney function in the river lamprey Lampetra fluviatilis adapted to fresh water. J. Exp. Biol. 85: 137-147.

Maetz J, Bourguet J, Lahlouh B and Hourdry J. (1964) Peptides neurohypophysarires et osmoregulation chez Carassius auratus. Gen. Comp. Endocrinol. 4: 508-522.

McVicar AJ and Rankin JC. (1985) Dynamics of glomerular filteration in the river lamprey, Lampetra fluviatilis L. Am. J. Physiol. 249: F132-138.

Morris R. (1958) The mechanism of marine osmoregulation in the lampern (Lampetra fluviatilis L.) and the causes of its breakdown during the spawning migration. J. Exp. Biol. 35: 649-665.

Norberg B, Björnsson B Th, Brown CL, Wichardt U-P, Deftos LJ and Haux C. (1989) Changes in plasma vitellogenin, sex steroids, calcitonin, and thyroid hormones related to sexual maturation in female brown trout (Salmo trutta). Gen. Comp. Endocrinol. 75: 316-326.

Peek WD and Youson JH. (1979) Ultrastructure of chloride cells in young adults of the anadromous sea lamprey, Petromyzon marinus L., in fresh water and during adaptation to sea water. J. Morphol. 160: 143164.

Rankin JC. (2002) Drinking in hagfishes and lampreys. Symp. Soc. Exp. Biol. 54: 1-17.

Sawyer WH, Uchiyama M and Pang PKT. (1982) Control of renal functions in lungfishes. Fed. Proc. 41: 23612364.
Suzuki M, Kubokawa K, Nagasawa $H$ andUrano A. (1995) Sequence analysis of vasotocin cDNAs of the lamprey, Lampetra japonica, and the hagfish, Eptatretus burgeri: Evolution of cyclostome vasotocin precursors. J. Mol. Endocrinol. 14: 67-77.

Suzuki N. (1995) Calcitonin-like substance in plasma of the hagfish, Eptatretus burgeri (Cyclostomata). Zool. Sci. 12: 607-610.

Suzuki N. (2001) Calcitonin-like substance in the plasma of Cyclostomata and its putative role. Comp. Biochem. Physiol. 129B: 319-326.

Suzuki N, Yamamoto K, Sasayama Y, Suzuki T, Kurokawa T, Kambegawa A, Srivastav Ajai K, Hayashi S and Kikuyama S. (2004) Possible direct induction by estrogen of calcitonin secretion from ultimobranchial cells in the goldfish. Gen. Comp. Endocrinol. 138: 121-127.

Takagi T, Sekiguchi T, Sasayama Y, Hattori A, Watanabe TX, Kitani Y, Tabuchi Y, Matsubara H, Srivastav Ajai K, Hai TN, Amornsakun, T and Suzuki N. (2019) Development of a system for measuring calcitonin in the stingray Dasyatisakajei (a cartilaginous fish): The possible involvement of stingray calcitonin in gonadal development. Int. Aqua. Res. 11:267-276.

Uchiyama M, Saito N, Shimada K and Murakami T. (1994) Pituitary and plasma vasotocin levels in the lamprey, Lampetra japonica. Comp. Biochem. Physiol. 107A: 23-26.

Wang PS, Tsai SC, Hwang GS, Wang SW, Lu CC, Chen JJ, Liu SR, Lee KY, Chien EJ, Chien CH, Lee HY, Lau CP and Tsai CL. (1994) Calcitonin inhibits testosterone and luteinizing hormone secretion through a mechanism involving an increase in cAMP production in rats. J. Bone Miner. Res. 9: 1583-1590.

Watts EG, Copp DH andDeftos LJ. (1975) Changes in plasma calcitonin and calcium during the migration of salmon. Endocrinology 96: 214-218.

Watzka M. (1933) VergleichendeUntersuchungenüber den ultimobranchialenKörper. Z. Mikrosk. Anat. Forsch. 34: 485-533.

Yamauchi $\mathrm{H}$, Orimo $\mathrm{H}$, Yamauchi $\mathrm{K}$, Takano $\mathrm{K}$ and Takahashi H. (1978) Increased calcitonin levels during ovarian development in the eel, Anguilla japonica. Gen. Comp. Endocrinol. 36: 526-529.

Watt GM and Brandwijk B. (1962) The Medicinal and Poisonous Plants of Southern and Eastern Africa. E.S. Livingstone Ltd, Edinburg, London; pp. 745. 